\title{
JOB SATISFACTION LEVEL DETERMINANT OF HYGIENE COLLEGE STAFF (STIKES) HANGTUAH PEKANBARU
}

\author{
Nofri Hasrianto
}

STIKES Al-Insyirah Pekanbaru

Email: nofrihasrianto@gmail.com

\begin{abstract}
Globalization era humans have very imperotant role. Factors that can arise motivation and spirit is sense job satisfaction. If there is dissatisfaction from labor hence it will adversely effect to his job causes job satisfaction reflect a person feeling to his job and all he face in his work environment. Problems in this research are to know job satisfaction level of hygiene college staff Hangtuah Pekanbaru and also determinant of job satisfaction.

Aims of this research is to know picture of job satisfaction and relevant factors with job satisfaction of hygiene vollege staff Hangtuah Pekanbaru in Riau Provice by using approach method Cross Sectional Study with 115 staff as sample. This research results are 50,4\% unsatisfactory respondent, and there are 49,6\% who satisfied. After conducted bivariate varible test which meaningful is marriage statue $P$ value 0,003 and OR 3,446 while unmeaning age $P$ value 0,264, gender $P$ value 0,776, period of work $P$ value 0,203, office statue $P$ value 0,890

Thereby researcher suggest that decision maker in STIKES Hangtuah give enough developing opportunities to develop both thinking in work and also in carrier, give light work than heavy work, provide sufficiet income hence jobs satisfaction will be realized and otherwise if income less hence jobs satisfactory will be less too.

Need an awareness for all respondent who not marriage that they need to contiuosly develob their skill and give solution each other between coworker if they met difficulties in their work cause seem that unmarried responder responsders tended to unsatisfied.
\end{abstract}

Keywords: Determinant, Hygiene, Job, Staff

\section{PENDAHALUAN}

Dalam era globalisasi sumber daya manusia mempunyai peranan yang sangat penting. Pada era ini ditandai dengan semakin tingginya kualitas sumber daya manusia dan persaingan merebut pangsa pasar tenaga kerja, hal ini berkaitan dengan adanya perdagangan bebas di kawasan Asia, AFTA (Asian Free Trade Assosiation) secara bertahap dan dimulai tahun 2003 Dalam AFTA akan tercipta lalu lintas arus barang dan jasa tanpa hambatan disuluruh pelosok dan kawasan bumi (Prawirosentoso, 1999). Dalam menghadapi hal ini negara-negara berkembang umumnya kurang siap, karena barang dan jasa yang dihasilkan di negara tersebut tidak mempunyai keunggulan komperatif dan kompetitif dibandingkan negaranegara maju. Ilyas (1996) mengemukakan bahwa dengan terbukanya pasar bebas berakibat tingginya kompetisi di sektor kesehatan. Hal ini sering menimbulkan kekhawatiran terhadap kemampuan kita untuk bersaing. Kekhawatiran ini disebabkan karena produktivitas dan kualitas sumber daya kesehatan yang masih rendah.
Selain itu, sejalan dengan kemajuan ilmu dan teknologi bidang kesehatan dan tuntutan masyarakat yang semakin tinggi akan kualitas pelayanan kesehatan, maka diperlukan sumber daya manusia dengan kesehatan yang semakin berkualitas. Tuntutan akan tenaga kesehatan yang berkualitas ini telah diantisipasi oleh Deparemen Kesehatan. Di dalam Pedoman Administrasi Penyelenggraan Pendidikan disebutkan bahwa tujuan pendidikan tenaga kesehatan adalah menghasilkan tenaga kesehatan yang terampil dan bermutu dalam jumlah yang cukup dan jenis yang sesuai dengan macam pekerjaan untuk memenuhi kebutuhan pelayanan kesehatan (Depkes, 1988)

Tujuan dari institusi Pendidikan Hangtuah Pekanbaru adalah untuk menghasilkan tenaga kesehatan yang siap untuk memenuhi sumber daya manusia dalam aspek bidang kesehatan, sebagai lembaga pendidik yang mampu menciptakan lulusan kesehatan profesional yang memiliki pengetahuan mengenai masalah umum kesehatan saat ini dan yang akan datang dan mampu melaksanakan peran dan fungsinya 
sebagai pelaksana teknis tenaga kesehatan baik dalam asuhan keperawatan, pengelola manajemen kesehatan, pendidikan kesehatan dan penelitian dalam bidang kesehatan

Untuk mencapai hal tersebut maka untuk Program Studi memerlukan elemen-elemen atau faktor pendukung dalam penyelenggaraan pendidikan seperti sarana prasarana (peralatan) yang mencukupi dan dalam kondisi yang baik, keuangan yang cukup dan jelas sumbernya, serta sumber daya manusia/ketenagaan terutama tenaga staf/dosen yang cukup jumlahnya dan memiliki kualifikasi pendidikan sesuai dengan standar yang ditentukan oleh Departemen Pendidikan. Keberadaan tenaga staf ini mempunyai peran yang amat strategis dan penting dalam upaya meningkatkan mutu pendidikan saat ini dan masa datang.

Menurut Howel dan Depboye (Munandar. 2001) kepuasan kerja merupakan hasil keseluruhan dari derajat suka atau tidak sukanya tenaga kerja terhadap berbagai aspek pekerjaanya, dengan kata lain kepuasan kerja menceminkan sikap tenaga kerja terhadap berbagai aspek dari pekerjaanya.

STIKes Hangtuah Pekanbaru merupakan salah satu institusi pendidikan kesehatan yang menyelenggarakan pendidikan kesehatan dengan 4 (empat) Program Studi antara lain Program Studi Ilmu Kesehatan Masyarakat (IKM), Program Studi Perekam dan Informatika Kesehatan (APIKES), Ilmu Keperawatan, dan Akademi Kebidanan. Yang setiap Program Studi mempunyai prasyarat SKS dan kewajiban yang telah diputuskan sesuai dengan kurikulum dan standar Departemen Pendidikan Masa pendidikan Ilmu Kesehatan Masyarakat (IKM) selama 4 tahun (8 semester), Perekam dan Informatika Kesehatan masa pendidikan 3 tahun (6 semester), Ilmu Keperawatan 4 tahun (8 semester) + Profesi 1,5 tahun (3 semester) dan Akademi Kebidanan 3 tahun (6 semester).

Sekolah Tinggi Ilmu Kesehatan (STIKes) Hangtuah Pekanbaru menyelenggarakan pendidikan kesehatan pada tahun 2002 dengan SK Mendiknas No 226/D/O/2002. Yayasan Hangtuah didirikan atas kerja sama dengan Dinas Kesehatan Provinsi Pemerintah Daerah
Pekanbaru dan Balai Pelatihan Kesehatan Masyarakat (BLKM) di Jakarta. Awal pendirian Yayasan Hangtuah. Program Studi yang direkomendasikan adalah Ilmu Kesehatan Masyarakat (IKM) dan Perekam dan Informatika Kesehatan (APIKES). Pada tahun 2006 menambah Program Studi Ilmu Keperawatan dan Akademi Kebidanan dengan No. SK. 83/D/O/2006 dan sampai saat ini mempunyai staf sebanyak 115 orang, dari masing-masing program studi selebihnya tenaga administrasi pusat, yaitu yang bertanggung jawab dengan pelaksanaan pendidikan keseluruhan.

Pada tahun 2002-2006 jumlah mahasiswa tidak terjadi kenaikan yang besar namun standar Dikti tetap mengharuskan jumlah pegawai harus sesuai dengan standarisasi yang ditentukan, pada tahun 2006-2007 jumlah mahasiswa mengalami kenaikan 745 orang yang begitu signifikan namun tahun ajran 2007-2008 menurun menjadi 456 orang dikarenakan jumlah SDM yang masih kurang untuk memenuhi standarisasi oleh Dikti.

Berdasarkan rata-rata jumlah mahasiswa dari tahun 2002-2006 sebanyak 544, pada tahun 2007 sebanyak 745, di tahun 2008 sebanyak 456. Terjadi penurunan tahun 2007-2008 sebanyak 289 mahasiswa Peningkatan tenaga staf yang keluar pada tahun 2006 sebanyak 10 orang, tahun 2007 sebanyak 16 orang, tahun 2008 sebanyak 24 orang dari total 115 orang staf. Disamping itu peningkatan pelanggaran terhadap peraturan yayasan yang diberlakukan kepada staf terlihat dari jumlah surat peringatan maupun teguran langsung HRD kepada Staf pada tahun 2008 sebanyak 23 kali peringatan yang diberikan kepada 16 staf dari data tersebut maka merupakan gambaran penurunan kerja staf.

Kepuasan kerja staf di keempat Program Studi tersebut perlu mendapat perhatian yang sungguh-sungguh dalam rangka meningkatkan semangat, kinerja dan kualitas kerja dari staf yang bersangkutan, agar kualitas pendidikan dan produk yang dihasilkan dapat diandalkan terutama dalam era persaingan dan kompetitif saat ini. Diharapkan tingkat kepuasan kerja staf senantiasa pada tingkatan kerja yang tinggi. Beberapa faktor yang diduga sebagai penyebab ketidakpuasan dan kepuasan kerja adalah dari 
faktor karakteristik demografi (usia, jenis kelamin, status perkawinan) sedangkan faktor lain kemungkinan dari faktor pekerjaan (masa kerja, status kepegawaian, penghasilan, beban kerja dan kesempatan berkembang).

Memperhatikan uraian dan penjelasan diatas, maka peneliti berminat untuk meneliti masalah kepuasan kerja terhadap staf/karyawan pada Stikes Hangtuah Pekanbaru provinsi Riau. Karena belum pernah ada yang meneliti masalah tersebut sebelumnya.

\section{METODE PENELITIAN}

Jenis penelitian ini adalah Analitik kuantitatif dengan menggunakan desain Cross sectional study yang dilaksanakan di STIKES Hangtuah Pekanbaru. Pada bula Juli 2009. Populasi dalam penelitian ini adalah seluruh staf Sekolah Tinggi Ilmu Kesehatan Hangtuah dasar penetaannya adalah surat keputusan yang ditetapkan oleh yayasan Hangtuah Pekanbaru sebanyak 115 orang. Instrumen yang digunakan berupa kuesioner/angket terstruktur.

\section{HASIL DAN PEMABAHASAN}

\section{Analisa Univariat}

Dari gambaran distribusi responden berdasarkan karakteristik diperoleh data bahwa sebagian besar berusia muda $(73,9 \%)$, kawin $(59,1 \%)$ dengan masa kerja kurang dari 3 tahun $(82,6 \%)$ dan berstatus pegawai tetap $(68,7 \%)$.

\section{Analisa Bivariat}

Proporsi staf yang merasa tidak puas pada kelompok umur muda sebanyak $54,1 \%$ dan responden yang berumur tua yang puas sebanyak $60,0 \%$. Berdasarkan uji statistik hubungan antara umur dengan kepuasan kerja di peroleh nilai $\mathrm{P}$ value 0,264 yang berarti tidak ada hubungan yang bermakna antara umur dengan kepuasan kerja.

Proporsi Responden staf berjenis kelamin perempuan yang tidak puas sebanyak $52,7 \%$ dan staf laki-laki yang puas $51,7 \%$ berdasarkan uji statistik hubungan antara jenis kelamin dengan kepuasan kerja diperoleh nilai $\mathrm{P}$ value 0,776 yang berarti tidak ada hubungan yang bermakna antara jenis kelamin dengan kepuasan kerja.

Proporsi responden yang tidak puas pada status responden tidak kawin $(68,1 \%)$ dan responden status kawin mempunyai kepuasan $(61,8 \%)$. Berdasarkan uji statistik hubungan atara status perkawinan dengan kepuasan kerja diperoleh nilai $\mathrm{P}$ value 0,003 yang berarti ada hubungan yang bermakna antara jeis kelamin dengan kepuasan kerja dan OR 3,446 yang artinya bahwa responden yang tidak kawin mepunyai kemungkinan tidak puas 3,446 kali lebih besar di bandingkan dengan responden yang sudah kawin.

Proporsi responden yang masa kerja baru yang tidak puas lebih besar $53,7 \%$ dan responden yang mempunyai masa kerja lama yang puas $65 \%$ uji statistik hubungan antara masa kerja dengan kepuasan kerja di peroleh nilai $\mathrm{P}$ value 0,203 yang berarti tidak ada hubungan yang bermakna antara masa kerja dengan kepuasan kerja.

Proporsi yang berdasarkan pada status kepegawaian kontrak mempunyai rasa tidak puas sebesar $52,8 \%$ dan status kepegawaian tetap yang puas $50,6 \%$, uji statistik hubungan antara status kepegawaian dengan kepuasan kerja diperoleh nilai $P$ value 0,890 yang berarti tidak ada hubungan yang bermakna antara masa kerja dengan kepuasan kerja

Tabel 1

Distribusi Responden Berdasarkan Umur dengan Kepuasan Kerja

\begin{tabular}{|c|c|c|c|c|c|c|c|c|}
\hline \multirow{3}{*}{ Umur } & \multicolumn{4}{|c|}{ Kepuasan Responden } & \multirow{2}{*}{\multicolumn{2}{|c|}{ Total }} & \multirow{3}{*}{$\begin{array}{c}\text { OR } \\
(95 \% \mathrm{CI}\end{array}$} & \multirow{3}{*}{$\begin{array}{c}\mathbf{P} \\
\text { value }\end{array}$} \\
\hline & \multicolumn{2}{|c|}{ Tidak puas } & \multicolumn{2}{|c|}{ Puas } & & & & \\
\hline & $\mathbf{N}$ & $\%$ & $\mathbf{N}$ & $\%$ & $\mathbf{N}$ & $\%$ & & \\
\hline $\begin{array}{c}\text { Muda (20-35 } \\
\text { thn) }\end{array}$ & 46 & 54,1 & 39 & 45,9 & 85 & 100 & $\begin{array}{l}1,769 \\
750\end{array}$ & \\
\hline Tua (> 35 thn) & 12 & 40,0 & 18 & 60,0 & 30 & 100 & (120) & 0,264 \\
\hline Total & 58 & 50,4 & 57 & 49,6 & 115 & 100 & & \\
\hline
\end{tabular}


Tabel 2

Distribusi Responden Berdasarkan Umur dengan Kepuasan Kerja

\begin{tabular}{|c|c|c|c|c|c|c|c|c|}
\hline \multirow{3}{*}{ Jenis kelamin } & \multicolumn{4}{|c|}{ Kepuasan Responden } & \multirow{2}{*}{\multicolumn{2}{|c|}{ Total }} & \multirow{3}{*}{$\begin{array}{c}\text { OR } \\
(95 \% \mathrm{CI}\end{array}$} & \multirow{3}{*}{$\begin{array}{c}\mathbf{P} \\
\text { value }\end{array}$} \\
\hline & \multicolumn{2}{|c|}{ Tidak puas } & \multicolumn{2}{|c|}{ Puas } & & & & \\
\hline & $\mathbf{N}$ & $\%$ & $\mathbf{N}$ & $\%$ & $\mathbf{N}$ & $\%$ & & \\
\hline Perempuan & 29 & 52,7 & 26 & 47,3 & 55 & 100 & 1,192 & \\
\hline Laki-laki & 29 & 48,3 & 31 & 51,7 & 60 & 100 & $(0,573-$ & 0,776 \\
\hline Total & 58 & 50,4 & 57 & 49,6 & 115 & 100 & $2,480)$ & \\
\hline
\end{tabular}

Tabel 3

Distribusi Responden Berdasarkan Status Perkawinan dan Kepuasan Kerja

\begin{tabular}{|c|c|c|c|c|c|c|c|}
\hline \multirow{3}{*}{$\begin{array}{c}\text { Status } \\
\text { perkawinan }\end{array}$} & \multicolumn{3}{|c|}{ Kepuasan Responden } & \multirow{2}{*}{\multicolumn{2}{|c|}{ Total }} & \multirow{3}{*}{$\begin{array}{l}\text { OR } \\
(95 \% \mathrm{CI}\end{array}$} & \multirow{3}{*}{$\begin{array}{l}P \\
\text { value }\end{array}$} \\
\hline & Tidak puas & 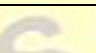 & Puas & & & & \\
\hline & $\mathbf{N} \quad \%$ & $\mathbf{N}$ & $\%$ & $\mathbf{N}$ & $\%$ & & \\
\hline Tidak kawin & $32 \quad 68,1$ & 15 & 31,9 & 47 & 100 & 3446 & \\
\hline Kawin & $26 \quad 38,2$ & 42 & 61,8 & 68 & 100 & $-3,446$ & 0,003 \\
\hline Total & $\begin{array}{ll}58 & 50,4 \\
\end{array}$ & 57 & 49,6 & 115 & 100 & & \\
\hline
\end{tabular}

Tabel 4

Distribusi Responden Berdasarkan Masa Kerja dan Kepuasan Kerja

\begin{tabular}{|c|c|c|c|c|c|c|c|c|c|}
\hline \multirow{3}{*}{\multicolumn{2}{|c|}{ Masa kerja }} & \multicolumn{4}{|c|}{ Kepuasan Responden } & \multirow{2}{*}{\multicolumn{2}{|c|}{ Total }} & \multirow{3}{*}{$\begin{array}{l}\text { OR } \\
(95 \% \mathrm{CI}\end{array}$} & \multirow{3}{*}{$\begin{array}{l}P \\
\text { value }\end{array}$} \\
\hline & & \multicolumn{2}{|c|}{ Tidak puas } & \multicolumn{2}{|c|}{ Puas } & & & & \\
\hline & & $\mathbf{N}$ & $\%$ & $\mathbf{N}$ & $\%$ & $\mathbf{N}$ & $\%$ & & \\
\hline \multicolumn{2}{|c|}{ Baru $(<3$ tahun $)$} & 51 & 53,7 & 44 & 46,3 & 95 & 100 & \multirow{3}{*}{$\begin{array}{l}2,163 \\
0,789-5,872\end{array}$} & \multirow{3}{*}{0,203} \\
\hline \multicolumn{2}{|c|}{ Lama ( $\geq 3$ tahun) } & 7 & 35,0 & 13 & 65,0 & 20 & 100 & & \\
\hline Total & & 58 & 50,4 & 57 & 49,6 & 115 & 100 & & \\
\hline
\end{tabular}

Tabel 5

Distribusi Responden Berdasarkan Status Kepegawaian dan Kepuasan Kerja

\begin{tabular}{|c|c|c|c|c|c|c|c|c|}
\hline \multirow{3}{*}{$\begin{array}{c}\text { Status } \\
\text { kepegawaian }\end{array}$} & \multicolumn{4}{|c|}{ Kepuasan Responden } & \multirow{2}{*}{\multicolumn{2}{|c|}{ Total }} & \multirow{3}{*}{$\begin{array}{l}\text { OR } \\
(95 \% \mathrm{CI}\end{array}$} & \multirow{3}{*}{$\begin{array}{l}P \\
\text { value }\end{array}$} \\
\hline & \multicolumn{2}{|c|}{ Tidak puas } & \multicolumn{2}{|c|}{ Puas } & & & & \\
\hline & $\mathbf{N}$ & $\%$ & $\mathbf{N}$ & $\%$ & $\mathbf{N}$ & $\%$ & & \\
\hline Kontrak & 19 & 52,8 & 17 & 47,2 & 36 & 100 & & \\
\hline Tetap & 39 & 49,4 & 40 & 50,6 & 79 & 100 & 1,140 & 0,890 \\
\hline Total & 58 & $\overline{50,4}$ & 57 & 49,6 & 115 & 100 & $0,3<1-2$ & \\
\hline
\end{tabular}

\section{a. Hubungan antara umur dengan kepuasan} kerja

Hasil penelitian ini tidak sesuai dengan Davis dan Newstom (Mahatmi, 1997) dikutip dari (amirfarouk, 2002)kepuasan kerja dipengaruhi oleh umur, makin tua umur seseorang biasanya cendrung lebih puas dengan pekerjaannya, hal ini disebabkan harapan mereka terhadap tempat kerja makin rendah dan karena lebih berpengalaman maka penyesuaian terhadap tempat kerja lebih baik. Menurut penelitian
Hayutunggal Tuswulandari (2004) yang menyatakan bahwa ada hubungan yang signifikan antara umur dengan kepuasan kerja, sedangkan sejalan dengan hasil penelitian Surtimanah (1997), Soepratman (1997) dan Retnasih (1995) dikutip dari Kridawati, Atik (2004), yang menyatakan bahwa tidak ada hubungan yang signifikan antara umur dengan kepuasan kerja.

Dengan demikian teori Gibson yang menyatakan bahwa variabel individu yaitu umur 
dapat mempengaruhi kepuasan kerja tidak terbukti dalam penelitian ini, hal ini mungkin disebabkan karena rata-rata umur responden $>35$ tahun umumnya sudah berkeluarga sehingga lebih bertanggung jawab dalam pekerjaan. selain itu mungkin juga disebabkan karena umur responden yang masih muda yaitu $\leq 35$ tahun dan baru keluar dari pendidikan sehingga kemampuan dan tanggung jawab dalam pekerjaan juga masih kurang, disamping itu kemungkinan hal ini juga bisa terjadi karena pengelompokkan umur yang tidak tepat atau kurang sesuai untuk mengukur kepuasan kerja

\section{b. Hubungan antara Jenis kelamin dengan Kepuasan Kerja}

Ilyas (1991) bahwa tidak ada perbedaan produktivitas antara pekerja wanita dan pria. Menurut Tricahyono (1996) dikutip dari (amirfarouk, 2002)bahwa wanita lebih puas dibandingkan dengan pria apa bila kelompok wanita tersebut menerima upah dan memiliki kedudukan sosial yang sama seperti kelompok pekerja pria.

Penelitian Helda (1999) secara statistik tidak ditemukan hubungan antara jenis kelamin dengan kepuasan kerja pada dosen tetap akper swasta di palembang. Hal ini memperlihatkan ada kesamaan hasil dengan apa yang telah peneliti temukan dengan hasil dari penelitian-peneliti terdahulu

Dalam hasil penelitian jenis kelamin tidak berhubungan dengan kepuasan kerja, tetapi bukan berarti faktor ini menjadi tidak penting dalam pembinaan pengelola institusi terhadap staf ataupun jika ada rencana melakukan rekrutmen, antara kedua jenis kelamin ini mempunyai nilai plus minusnya terhadap berbagai aspek pekerjaan. Jika suatu pekerjaan memerlukan gerak atau mobilitas yang tinggi dengan beban yang berat misalnya dalam hal penyediaan alat-alat praktek atau penyediaan tempat untuk pembelajaran mahasiswa, tentu yang diperlukan adalah tenaga staf laki-laki, tetapi jika bidang pekerjaan seperti keuangan, tata ruang atau yang berhubungan langsung dengan mahasiswa dalam penyelesaianya diperlukan kesabaran, lemah lembut dan disiplin yang tinggi, yang cocok kebanyakan adalah kaum perempuan.

\section{c. Hubungan antara status perkawinan dengan kepuasan kerja}

Siagian (1995) menyatakan status perkawinan seseorang berpengaruh terhadap perilaku seseorang dalam kehidupan organisasinya, baik secara positif maupun negatif, demikian juga terhadap kepuasan kerja. Penelitian oleh Yamashita (1995) untuk menilai kepuasan perawat di Jepang menemukan bahwa status perkawinan merupakan faktor penting yang berpengaruh terhadap kepuasan kerja.

Mencari pasangan hiduppun menjadi persoalan, menjadi suatu pertanyaan apakah akan mendapat pasangan yang cocok dan sesuai atau sebaliknya, semua persoaalan tersebut menjadi besar jika tidak mampu mencari alternatif pemecahannya, dan dampaknya tentu terhadap pekerjaan yang menjadi tugas pokok dan fungsi dari yang bersangkutan, sehingga akan berpengarauh terhadap kepuasan kerja.

\section{d. Hubungan antara masa kerja dengan kepuasan kerja}

Hasil penelitian ini tidak sesuai dengan Hasil penelitian Hick dan Galwt (Bairizal, 2002) menyertakan bahwa faktor yang menimbulkan kepuasan kerja adalah lamanya kerja seseorang didalam bekerja, bahwa makin lama seseorang bekerja disuatu tempat maka akan mempunyai banyak pengalaman, sehingga banyak pertimbangan dalam hal memperoleh kepuasan kerja

Dari beberapa penelitian menunjukkan bahwa kepuasan kerja relatif tinggi pada waktu permulaan, kemudian menurun secara bertahap antara lima atau delapan tahun, setelah itu secara bertahap dirasakan kembali ketika masa kerja telah melebihi delapan tahun. Dan tingkat kepuasan kerja tertinggi dicapai setelah masa kerja dua puluh tahun. Manurut MC Cormick dan Ilgen (Diana, 1999) kepuasan kerja merupakan keseimbangan antara masukan dan imbalan dimana pengalaman kerja merupakan salah satu faktor yang termasuk didalam masukan yang mempunyai hubungan dengan kecenderungan tingkat kepuasan kerja 
Dengan bertambahnya masa kerja atau pengalaman kerja sementara yang dikerjakan hanya yang itu-itu saja dalam arti kata rutinisme belaka tanpa ada variasi terhadap pekerjaan, maka disini akan timbul rasa jenuh atau bosan apalagi tidak diiringi oleh peningkatan kesejahteraan dari pihak pengelola organisasi/institusi. Biasanya pekerjaan yang menjadi tugasnya tetap akan dikerjakan tetapi sifatnya hanya rutinitas saja, tidak ada upaya peningkatan atau pengembangan, akibatnya sudah dapat ditebak bahwa mutu dari pekerjaan tersebut tentu tidak akan baik malah cenderung menurun, dan hal demikian menunjukkan bahwa tingkat kepuasan kerja juga menurun.

e. Hubungan antara status kepegawaian dengan kepuasan kerja.

Menurut lock (Ashar Sunyoto, 2001) bahwa ciri-ciri instrinsik dari pekerjaaan yang menentukan kepuasan kerja seseorang adalah keanekaragaman pekerjaan, beban kerja atau jumlah pekerjaan, kesulitan, tanggung jawab, kondisi terhadap metoda pekerjaan. Pendapat tersebut menjelaskan bahwa banyaknya ragam keterampilan yang digunakan dan diperlukan untuk melakukan pekerjaan makin mengurangi rasa membosankan terhadap pekerjaan tersebut.

Belum diperoleh informasi tentang adanya penelitian terdahulu mengenai hubungan antara status kepegawaian dengan kepuasan kerja, demikian juga pendapat-pendapat dari para ahli belum peneliti temukan sehingga agak sulit membuat perbandingan hasil penelitian ini. Namun berdasarkan asumsi peneliti, hasil penelitian ini barangkali ada kaitannya dengan sistem penempatan atau rekrutmen yang diterapkan terhadap tenaga staf.

\section{KESIMPULAN DAN SARAN}

\section{Kesimpulan}

Berdasarkan hasil penelitian yang dilakukan maka peneliti menyimpulkan sebagai berikut:

a. Dalam penelitian ini kepuasan kerja diukur berdasarkan seberapa besar persepsi responden tetang beban kerja, penghasilan dan kesempatan berkembang dapa memberikan rasa puas dalam pekerjaanya. b. Hasil penelitian yang dilakukan yaitu responden yang tidak puas ada $50.4 \%$ dan yang puas sebanyak $49,6 \%$

c. Setelah dilakukan uji bivariat hanya variabel status perkawinan yang bermakna dengan kepuasan yaitu dengan nilai $\mathrm{P}$ value 0,0003 dan OR 3,446

\section{Saran}

Berdasarakan hasil penelitian ini, maka ada beberapa hal yang dapat disarankan:

Untuk pengurus/pengelola yayasan pendidikan Stikes Hangtuah Pekanbaru, dalam rangka meningkatkan mutu penyelenggaraan pendidikan hendaknya memperhatikan hal-hal sebagai berikut:

a. Agar pengambil keputusan di stikes Hangtuah memberikan kesempatan berkembang yang cukup untuk dapat mengembangkan pemikiran dalam pekerjaan maupun dalam karir, pendidikan maupun seminar, lokakarya serta pelatihan-pelatihan, yang nantinya dapat menunjang dalam pekerjaan.

b. Memberikan pekerjaan yang ringan lebih puas dibandingkan dengan responden yang mengatakan beban kerja berat, namun tetap mempunyai rasa tanggung jawab untuk menyelesaikan pekerjaan.

c. Memberikan penghasilan cukup maka kepuasan tercipta demikian sebaliknya apa bila penghasilan kurang maka kepuasan kerja staf akan berkurang, maka diharapkan agar yayasan dapat memperhatikan kembali penghasilan yang sesuai dengan kebutuhan staf.

\section{UCAPAN TERIMA KASIH}

Kepada Ketua STIKES Hangtuah Pekanbaru yang telah memberikan kesempatan kepada peneliti untuk melaksanakan penelitian, Dekan Fakultas Magister Kesehata Masyarakat Universitas Respati Indonesia, atuna, Serta kepada responden dan juga orang-orang yang banyak berperan hingga penelitian sehingga dapat diselesaikan. 
DAFTAR PUSTAKA

Anggraini ulfa, 1998 Hubungan karakteristik perawat dan kepuasan kerja dengan harapan perawat terhadap gaya kepemimpinan dan kegiatan manajerial kepala ruangan rawat ruang pavilyun Kartika RSPAD Gatot Subroto, FKM UI Jakarta

As'ad M, 1984 Psikologi Industri edisi revisi Liberty Yogyakarta, 1991 Seri ilmu sumber daya manusia: Psikologi Industri, liberty, yogyakarta, 1995 Psikologi Industri "Edisi Keempat" cetakan kedua, Liberty, Yogyakarta

Artikel Wang

Muba htpp://wangmuba.com/2009/02/18/kepu asan-kerja/Kepuasan Kerja 2009

Amir farouk tahun 2002 Faktor-faktor yang berhubungan dengan kepuasan kerja staf pengajar tetap akademi keperawatan milik swasta dan pemda propinsi jambi tahun 2001 FKM UI 2001

Davis, K \& New strom, 1985 Organisation Behavior Terjemahan: Dharma A (Edisi Ketujuh) 1996 "perilaku dan organisasi" Penerbit Erlangga, Jakarta

Djayusman, MS, 1996 Faktor-faktor yang berhubungan dengan Motivasi Kerja Perawat di Paviliun khusus Swasta RSCM, Jakarta, FKM-UI

Direktorat Jenderal Perguruan Tinggi http://www..unissula.ac.id/file/pedoman \%20pembukaan\%program\%studi.docPe doman Pembukaan Program Studi Dan /Atau Jurusan 